\title{
Evaluation of Several Minor Alkaloid Levels in Tobacco with Separation of R- and S-Nornicotine *
}

\author{
by Serban C. Moldoveanu \\ R.J. Reynolds Tobacco Co., 950 Reynolds Blvd., Winston-Salem, NC 27105, USA
}

\begin{abstract}
SUMMARY
The chiral separation of minor alkaloids from tobacco is of interest because $\mathrm{R}$ and $\mathrm{S}$ isomers of these compounds have differences in their physiological activity. This difference is also reflected in the physiological properties of tobaccospecific $N^{\prime}$-nitrosamines (TSNAs), in particular that of $N^{\prime}$ nitrosonornicotine. This compound results mainly from nornicotine nitrosation. The previously reported analytical techniques for the enantiomer separation of minor alkaloids have various shortcomings, such as the need for bidimensional chromatography or poor enantiomer separation. A new method for the analysis of nornicotine, anabasine and anatabine has been developed, based on an original derivatization and a simple gas chromatography/mass spectrometry (GC/MS) analysis. The method allows separate quantitation of S-nornicotine and Rnornicotine, and the analysis of anabasine and anatabine (without isomer separation). It was found that the proportion of S-nornicotine in the total nornicotine present in tobacco varies, depending on the tobacco type, between $52.6 \%$ for a flue-cured tobacco to $91.4 \%$ for a Burley. Green tobaccos (freeze dried) showed lower levels of minor alkaloids and S-nornicotine accounted for between $31.6 \%$ to $43.8 \%$ of the total nornicotine (in the analyzed samples). [Beitr. Tabakforsch. Int. 25 (2013) 649-659]
\end{abstract}

\section{ZUSAMMENFASSUNG}

Die chirale Trennung von Nebenalkaloiden von Tabak ist von Interesse, da die R- und S-Isomere dieser Verbindungen Unterschiede in der physiologischen Aktivität aufweisen. Diese Unterschiede spiegeln sich auch in den physiologischen Eigenschaften von tabakspezifischen $N$-Nitrosaminen (TSNA) insbesondere bei $N$-Nitrosonornikotin wider. Diese Verbindung entsteht im Wesentlichen bei der Nitrosierung von Nornikotin. Die bisher beschriebenen Analysetechniken zur Enatiomerentrennung von Nebenalkaloiden haben diverse Mängel wie die Notwendigkeit der zweidimensionalen Chromatographie oder eine schlechte Enantiomerentrennung. Es wurde eine neue Methode zur Analyse von Nitrosonornikotin, Anabasin und Anatabin entwickelt, die auf einer herkömmlichen Derivatisierung und einer einfachen Analyse mittels Gaschromatographie-Massenspektrometrie (GC/MS) beruht. Die Methode ermöglicht die separate Quantifizierung von SNornikotin und R-Nornikotin sowie die Analyse von Anabasin und Anatabin (ohne Isomerentrennung). Hierbei wurde festgestellt, dass der Anteil von S-Nornikotin am Gesamtnornikotin im Tabak je nach Tabaksorte zwischen $52,6 \%$ bei heißluftgetrocknetem Tabak und $91,4 \%$ bei Burleytabak variiert. In grünen Tabaksorten (gefriergetrocknet) fanden sich geringere Mengen an Nebenalkaloiden und der Anteil von S-Nornikotin am Gesamtnornikotin lag (bei den analysierten Proben) zwischen 31,6\% und 43,8\%. [Beitr. Tabakforsch. Int. 25 (2013) 649-659]

\section{RESUME}

La séparation chirale des alcaloïdes mineurs du tabac présente un intérêt car les isomères $\mathrm{R}$ et $\mathrm{S}$ de ces composés présentent des différences dans leurs activités physiologiques. Ces différences se reflètent également dans les propriétés physiologiques des $N$-nitrosamines spécifiques du tabac (TSNA), en particulier celles de la $N$-nitrosonornicotine. Ce composé est principalement issu de la nitrosation de la nornicotine. Les techniques analytiques précédemment rapportées pour la séparation des énantiomères d'alcaloïdes mineurs présentent divers manques, comme le besoin d'une chromatographie bidimensionnelle ou une mauvaise séparation des énantiomères. Une nouvelle méthode d'analyse de la nornicotine, de l'anabasine et de l'anatabine a été mise au point, basée sur une dérivatisation originale et une simple analyse par chromatographie en phase gazeuse/spectrométrie de masse. La méthode permet une quantification séparée de la (S)-nornicotine et de la (R)-nornicotine ainsi que l'analyse de l'anabasine et de l'anatabine (sans séparation des isomères). Les résultats 
obtenus montrent que la proportion de (S)-nornicotine dans la nornicotine totale présente dans le tabac varie selon le type de tabac entre $52,6 \%$ pour un tabac blond et $91,4 \%$ pour un Burley. Les tabacs verts (lyophilisés) ont montré des teneurs inférieures en alcaloïdes mineurs et que la (S)nornicotine constitue entre $31,6 \%$ et $43,8 \%$ de la nornicotine totale (dans les échantillons analysés). [Beitr. Tabakforsch. Int. 25 (2013) 649-659]

KEYWORDS: Minor alkaloids, tobacco, S-nornicotine, Rnornicotine

\section{INTRODUCTION}

Analysis of minor alkaloids in tobacco has been the subject of numerous studies (1-7). These compounds are of particular interest for various reasons including potency toward nicotinic cholinergic receptors (8), propensity of formation of tobacco-specific nitrosamines (TSNAs) (9-12), and sensory properties $(8,13)$. The chiral separation of minor alkaloids from tobacco has also been of interest since the physiological activity of the enantiomers of these compounds have been shown to be different $(14,15)$. This difference in enantiomer activity is also reflected in the physiological properties of TSNAs, in particular that of $N^{\prime}$-nitrosonornicotine (NNN) $(16,17)$. NNN results mainly from the nitrosation of nornicotine present in tobacco and the $\mathrm{R} / \mathrm{S}$ configuration is not changed during nitrosation. This compound and 4 (methyl-N'-nitrosamino)-1-(3-pyridyl)-1-butanone (NNK) are the most abundant suspected carcinogens in tobacco. Although tobacco contains $N^{\prime}$-nitrosoanatabine (NAT) and smaller quantities of $N^{\prime}$-nitrosoanabasine (NAB), these two compounds are not classifiable as to their carcinogenicity to humans (IARC Group 3) and are of lower interest $(18,19)$. For this reason, the analysis of minor alkaloids with particular interest in the enantiomer separation of nornicotine has been the subject of several published studies (20-24). However, the previously reported analytical techniques for the enantiomer separation of minor alkaloids have various shortcomings. An early study concerning the separation of enantiomers of nornicotine, anatabine and anabasine in tobacco (21) was based on fractional crystallization of S6,6-dinitro-2,2'-diphenic acid and R-6,6-dinitro-2,2'diphenic acid derivatives of the minor alkaloids. More modern methods use direct phase high-performance liquid chro- matography (HPLC) with modest separation of nornicotine enantiomers (22), or two GC chiral columns without achieving baseline separation of R/S nornicotine isomers (23), or more complex procedures such as derivatization plus bidimensional GC separation (24). A new technique for analysis of minor alkaloids in tobacco with the separation of $\mathrm{R} / \mathrm{S}$ enantiomers of nornicotine has been developed and is described in detail.

\section{EXPERIMENTAL}

\section{Chemicals}

The solvents methyl tert-butyl ether, pyridine, and the reagent isobutyl chloroformate were obtained from Aldrich (Aldrich, Milwaukee, WI 53201, USA). The minor alkaloid standards were obtained from TRC (Toronto Research Chemicals, Toronto, ON M3J 2J8, Canada).

\section{Minor alkaloid extraction from the tobacco sample}

The extraction of minor alkaloids from the tobacco sample was performed following a common procedure recommended in the literature $(6,25)$. The extraction started with $0.2 \mathrm{~g}$ of a tobacco sample (as is), which was weighed with precision of $0.1 \mathrm{mg}$. To this sample, $0.5 \mathrm{~mL}$ of aqueous $1 \mathrm{~N} \mathrm{NaOH}$ was added to achieve sample wetting, and the sample was allowed to stand at room temperature for $15 \mathrm{~min}$. The purpose of this step was to transform any minor alkaloids present as salts into their base forms. The alkaline tobacco slurry was extracted with $4.0 \mathrm{~mL}$ of methyl tert-butyl ether (MTBE) containing $125 \mu \mathrm{g} \mathrm{mL}^{-1}$ ethyl quinoline-3-carboxylate as an internal standard. The extraction was performed on a mechanical shaker for $30 \mathrm{~min}$. After the extraction, the MTBE solution was filtered into a $4 \mathrm{~mL}$ vial through a $0.45 \mathrm{~mm}$ PVDF Whatman autovial (Whatman, Clifton, NJ, 07014, USA) in which was placed about $1 \mathrm{~g}$ of anhydrous $\mathrm{Na}_{2} \mathrm{SO}_{4}$. The solution of the extracted samples could be kept in a refrigerator for several weeks for further utilization, providing that the vial was well capped and no MTBE evaporation took place. The extraction efficiency using this procedure was not verified in this study, since it has been proven for the extraction of minor alkaloids in other published reports (see e.g., (6)).

Table 1. Parameters for the GC/MS analysis (Method 1).

\begin{tabular}{|c|c|c|c|}
\hline Parameter & Description & Parameter & Description \\
\hline Initial oven temperature & $50^{\circ} \mathrm{C}$ & Flow mode & Constant flow \\
\hline Initial time & $1.0 \mathrm{~min}$ & Flow rate & $1.1 \mathrm{~mL} / \mathrm{min}$ \\
\hline Oven ramp rate & $10^{\circ} \mathrm{C} / \mathrm{min}$ & Nominal initial pressure & 7.75 psi \\
\hline Oven temperature & $230^{\circ} \mathrm{C}$ & GC outlet & MSD \\
\hline Final time & $10 \min$ & Outlet pressure & Vacuum \\
\hline Total run time & $29.0 \mathrm{~min}$ & MSD transfer line temperature & $250^{\circ} \mathrm{C}$ \\
\hline Inlet temperature & $250^{\circ} \mathrm{C}$ & Ion source temperature & $230^{\circ} \mathrm{C}$ \\
\hline Inlet mode & Splitless & Quadrupole temperature & $150^{\circ} \mathrm{C}$ \\
\hline Purge off time & $0.5 \min$ & MSD EM gain & 1.75 \\
\hline Carrier gas & Helium & MSD solvent delay & $10.0 \mathrm{~min}$ \\
\hline Injection volume & $1.0 \mu \mathrm{L}$ & Mass range & 29-550 a.u. \\
\hline
\end{tabular}




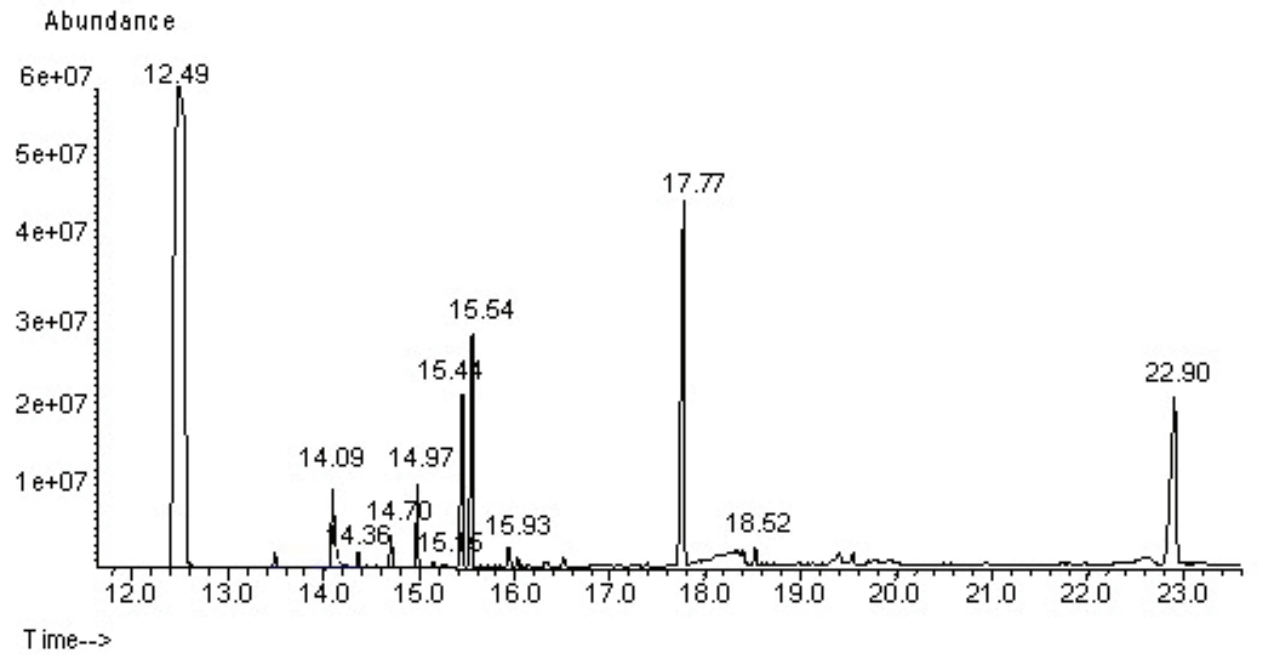

Figure 1. Typical chromatogram for a Burley tobacco extract without isomers separation. Peak identification is shown in Table 2.

Table 2. List of compounds of interest shown in the chromatogram for a Burley tobacco extract.

\begin{tabular}{|c|c|c|c|c|}
\hline No. & $\begin{array}{l}\text { Ret. time } \\
\min \end{array}$ & Compound name & CAS No. & MW \\
\hline 1 & 12.49 & Nicotine & $54-11-5$ & 162 \\
\hline 2 & 14.09 & Nornicotine & $494-97-3$ & 148 \\
\hline 3 & 14.36 & Myosmine & $532-12-7$ & 146 \\
\hline 4 & 14.70 & Anabasine & $494-52-0$ & 162 \\
\hline 5 & 14.97 & Hydrocarbon & & \\
\hline 6 & 15.15 & $\beta$-Nicotyrine & $487-19-4$ & 158 \\
\hline 7 & 15.44 & Anatabine & $581-49-7$ & 160 \\
\hline 8 & 15.54 & Neophytadiene & 504-96-1 & 278 \\
\hline 9 & 15.93 & 2,3'-Bipyridine & $581-50-0$ & 156 \\
\hline 10 & 17.77 & $\begin{array}{l}\text { 3-Quinolinic acid ethyl } \\
\text { ester (I.S.) }\end{array}$ & $50741-46-3$ & 201 \\
\hline 11 & 18.52 & Cotinine & $486-56-6$ & 176 \\
\hline 12 & 22.90 & 4,8,14-Duvatriene-1,3-diol & $7220-78-2$ & 306 \\
\hline
\end{tabular}

\section{GC/MS analysis without enantiomer separation (Method 1)}

The analysis of the level of minor alkaloids in the tobacco extract, without the separation of enantiomers can be carried out following a procedure adapted from the literature (6). The instrument used for the analysis was a GC/MS 5973/6890 system from Agilent (Agilent, Wilmington, DE 19808, USA).
The separation was performed on a ZB-50 capillary column $30 \mathrm{~m} \times 0.25 \mathrm{~mm}$ i.d., with $0.25 \mathrm{~mm}$ film thickness from Phenomenex (Torrance, CA 905010, USA). The separation conditions are given in Table 1 . In the conditions described in Table 1, a typical Burley tobacco extract generates the chromatogram shown in Figure 1. The peak identification is shown in Table 2.

The simultaneous quantitation of nicotine and of minor alkaloids is not feasible by this method, because the resulting nicotine chromatographic peak is overloaded. Among the minor alkaloids, only nornicotine, anabasine and anatabine were measured. The measurement was performed using calibration curves for specific extracted ion areas. The levels of compounds in the injected solutions were obtained from six standards in the range of $7.8 \mu \mathrm{g} \mathrm{mL}^{-1}$ to $250 \mu \mathrm{g} \mathrm{mL}^{-1}$. The internal standard was used only for the verification of the repeatability of the analysis and not for normalization. The ions used for quantitation, the equations used for the calibration, and the regression coefficient $\mathrm{R}^{2}$ values for the trendline are given in Table 3.

GC/MS analysis with nornicotine enantiomer separation (Method 2)

For the separation of minor alkaloids nornicotine, anabasine and anatabine and simultaneously of R- and S-nornico-

Table 3. The ions used for quantitation, the equations used for the calibration, and $\mathbf{R}^{2}$ values for the trendline in Method 1.

\begin{tabular}{l|c|c|c|c|c}
\hline No. & Compound & Quantitation ion & Confirmation ions & Equation* $^{*}$ & $R^{2}$ \\
\hline 1 & Nornicotine & 119 & $147,148,70$ & Y $=2.4569 \mathrm{e}-5 \mathrm{X}$ & 0.9897 \\
2 & Anabasine & 162 & $133,161,84$ & $\mathrm{Y}=2.9099 \mathrm{e}-5 \mathrm{X}$ & 0.9977 \\
3 & Anatabine & 160 & $105,159,131$ & $\mathrm{Y}=2.9596 \mathrm{e}-5 \mathrm{X}$ & 0.9903 \\
4 & 3-Quinolinic acid ethyl ester (I.S.) & 156 & $201,128,173$ & & \\
\hline
\end{tabular}

${ }^{*}$ Note: $\mathrm{Y}$ represents the amount in $\mathrm{mg} \mathrm{mL}^{-1}$ and $\mathrm{X}$ the peak area. 
tine, a derivatization step was necessary. For this purpose, the minor alkaloids containing active hydrogens in their molecules were derivatized with isobutyl chloroformate (isobutyl chlorocarbonate). With nornicotine, for example, isobutyl chloroformate reacts as follows:<smiles>[CH]C(=O)OCC(C)COC(=O)N1CCCC1c1ccncc1CC(C)COC(=O)[O-]</smiles>

The separation of the derivatized compounds and of those not derivatized (since they do not have active hydrogens) was performed on a chiral column. Only the separation of $\mathrm{R}$ - and S-nornicotine was of interest in the study. The separation of R- and $\mathrm{S}$-anabasine and $\mathrm{R}$ - and $\mathrm{S}$-anatabine was not pursued.

For the derivatization, $0.6 \mathrm{~mL}$ tobacco extract in MTBE was placed in a $1.5 \mathrm{~mL} \mathrm{GC}$ vial and was treated with $20 \mu \mathrm{L}$ pyridine and $10 \mu \mathrm{L}$ isobutyl chloroformate. The solution became turbid, but after being kept at room temperature for about $15 \mathrm{~min}$, the solution cleared and could directly be used for injection into the GC/MS system. The column used for the separation was a Rt-BDEXsm $30 \mathrm{~m}$ $\times 0.25 \mathrm{~mm}$ i.d., with $0.25 \mathrm{~mm}$ film thickness from Restek (Restek, Bellefonte, PA 16823, USA). The instrument used for the analysis of the minor alkaloids was a GC/MS 5973/6890 system from Agilent. The conditions for the GC/MS analysis are described in Table 4 and a typical Burley tobacco extract chromatogram is shown in Figure 2. The peak identification is shown on the figure. The separation of $\mathrm{R}$ - and S-nornicotine derivatives was good (resolution $\mathrm{R} \approx 1$ ), and allowed for the integration of the $\mathrm{R}$ and $\mathrm{S}$ peaks separately. Figure 3 shows an expanded portion of the chromatogram from Figure 2, with separated nornicotine isomers.

The spectra of isobutyl chloroformate derivatives of nornicotine, anabasine and anatabine have not been reported previously in the literature. These spectra are shown in Figures 4, 5, and 6, respectively. The structures of some of the main fragments corresponding to EI+ mass spectra are also shown in each figure.
The quantitation of R-nornicotine, S-nornicotine, R/Sanabasine, and R/S-anatabine was performed using calibration with a set of 6 derivatized standards with concentrations between $250 \mu \mathrm{g} \mathrm{mL} \mathrm{mL}^{-1}$ and $7.8 \mu \mathrm{g} \mathrm{mL} \mathrm{mL}^{-1} \mathrm{R} / \mathrm{S}$ nornicotine, $\mathrm{R} / \mathrm{S}$-anabasine, and $\mathrm{R} / \mathrm{S}$-anatabine. The internal standard was used only for the verification of the repeatability of the analysis but not for normalization. The ions used for quantitation, the equations used for the calibration, and the $\mathrm{R}^{2}$ values for the trendline are given in Table 5 .

The analytical procedure was further tested for stability of the derivatized analytes over time, and for the analysis repeatability. For this purpose, two samples, a Burley and a flue-cured tobacco were analyzed in duplicate over a period of $24 \mathrm{~h}$ after derivatization. The results are shown in Table 6, which gives the average of measurements and their relative standard deviations (RSD\%). The RSD\% for the total average was taken between the averages for different waiting periods. As shown in Table 6, the samples are stable for about $24 \mathrm{~h}$ and can be analyzed in this interval of time with good precision. However, a slight decrease in the results is still noticed as a general trend. For this reason, after the derivatization is performed, it is not recommended to analyze the samples after $24 \mathrm{~h}$.

Besides the linearity and stability, a further validation of Method 2 was performed to establish the limit of detection (LOD) and limit of quantitation (LOQ) for the method. For this purpose, five repeated injections of the lowest standard $\left(7.8 \mu \mathrm{g} \mathrm{mL}^{-1}\right)$ were carried out. LOD was estimated from $3 \times$ standard deviation (SD) and LOQ from $10 \times$ SD. The results are shown in Table 7 . It can be concluded that Method 2 showed good selectivity, stability, linearity, and appropriate LOQ values for the quantitation of R- and Snornicotine, anabasine and anatabine in tobacco.

\section{RESULTS AND DISCUSSION}

The two methods for minor alkaloids analysis have been applied for the measurement of nornicotine (one method with $\mathrm{R}$ and $\mathrm{S}$ separation), anabasine and anatabine in a series of tobacco samples. These tobaccos are described in Table 8, and they represent a wide range of samples, including different types of tobacco.

Table 4. Parameters for the GC/MS analysis (Method 2).

\begin{tabular}{|c|c|c|c|}
\hline Parameter & Description & Parameter & Description \\
\hline Initial oven temperature & $50^{\circ} \mathrm{C}$ & Purge off time & $0.5 \min$ \\
\hline Initial time & $2.0 \mathrm{~min}$ & Carrier gas & Helium \\
\hline Oven ramp rate & $30^{\circ} \mathrm{C} / \mathrm{min}$ & Injection volume & $1 \mu \mathrm{L}$ \\
\hline Oven temperature & $160{ }^{\circ} \mathrm{C}$ & Flow mode & Constant flow \\
\hline Final time first ramp & $9 \min$ & Flow rate & $1.0 \mathrm{~mL} / \mathrm{min}$ \\
\hline Oven ramp rate & $1^{\circ} \mathrm{C} / \mathrm{min}$ & Nominal initial pressure & 7.75 psi \\
\hline Oven temperature & $205^{\circ} \mathrm{C}$ & GC outlet & MSD \\
\hline Final time & $0 \mathrm{~min}$ & Outlet pressure & Vacuum \\
\hline Oven ramp rate & $20^{\circ} \mathrm{C} / \mathrm{mim}$ & MSD transfer line temperature & $250{ }^{\circ} \mathrm{C}$ \\
\hline Oven final temperature & $225^{\circ} \mathrm{C}$ & Ion source temperature & $230^{\circ} \mathrm{C}$ \\
\hline Final time & $4.33 \mathrm{~min}$ & Quadrupole temperature & $150{ }^{\circ} \mathrm{C}$ \\
\hline Total run time & $70.0 \mathrm{~min}$ & MSD EM gain & 1.75 \\
\hline Inlet temperature & $230^{\circ} \mathrm{C}$ & MSD solvent delay & $10.0 \mathrm{~min}$ \\
\hline Inlet mode & Splitless & Mass range & 29-350 a.u. \\
\hline
\end{tabular}




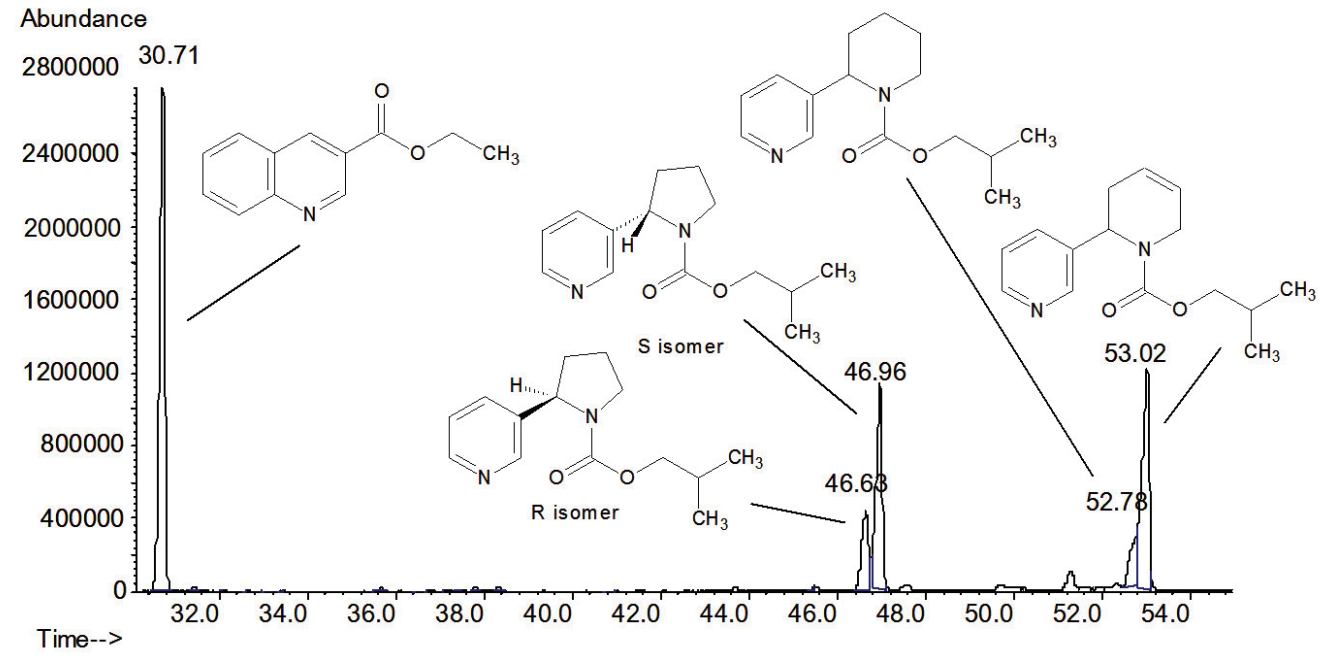

Figure 2. Typical chromatogram for a Burley tobacco extract derivatized with isobutyl chloroformate and the separation of R-and S-nornicotine.

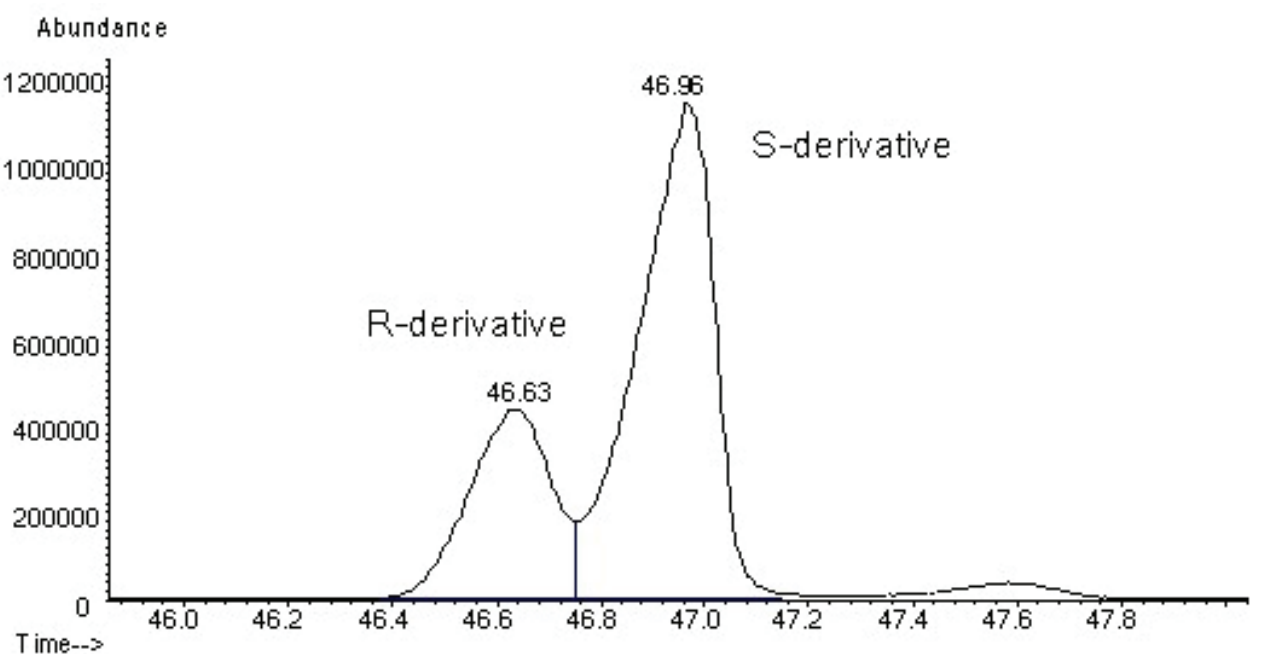

Figure 3. Portion of the chromatogram displayed in Figure 2, showing the separation of R-and S-nornicotine derivatives.

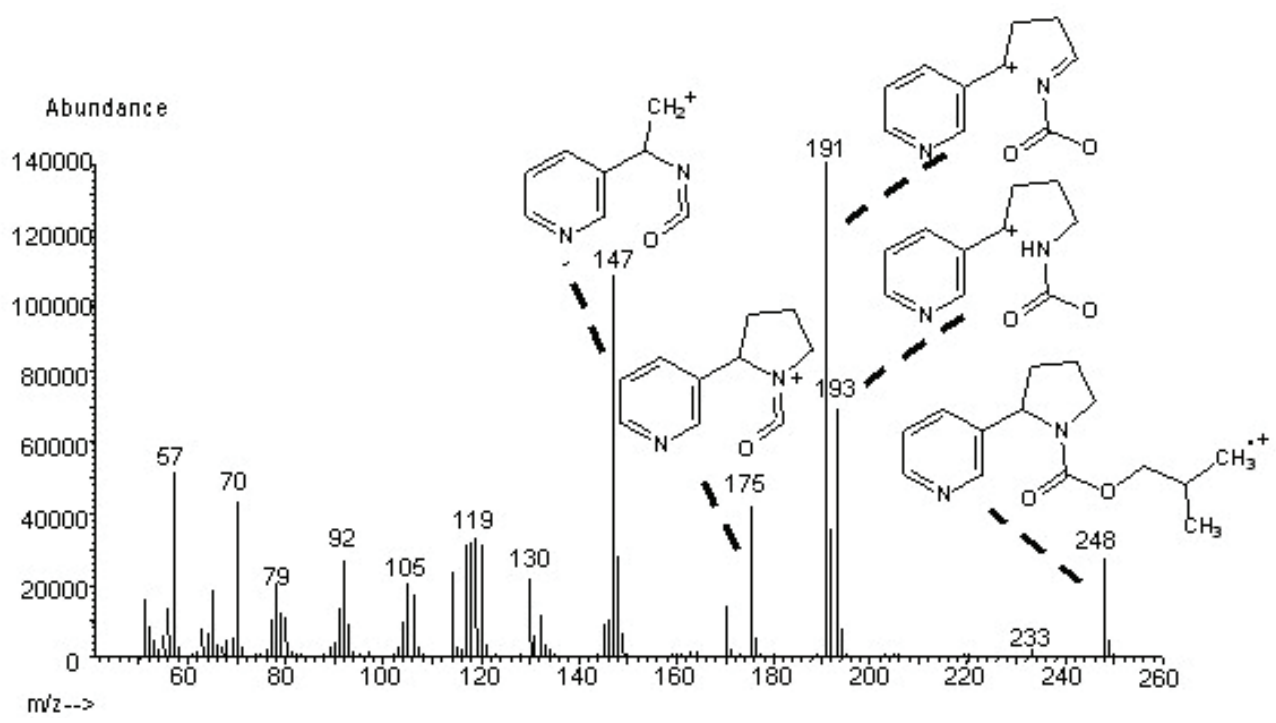

Figure 4. Mass spectrum of isobutyl chloroformate derivative of nornicotine or 2-methylpropyl 2-(pyridin-3-yl)pyrrolidine-1-carboxylate. 


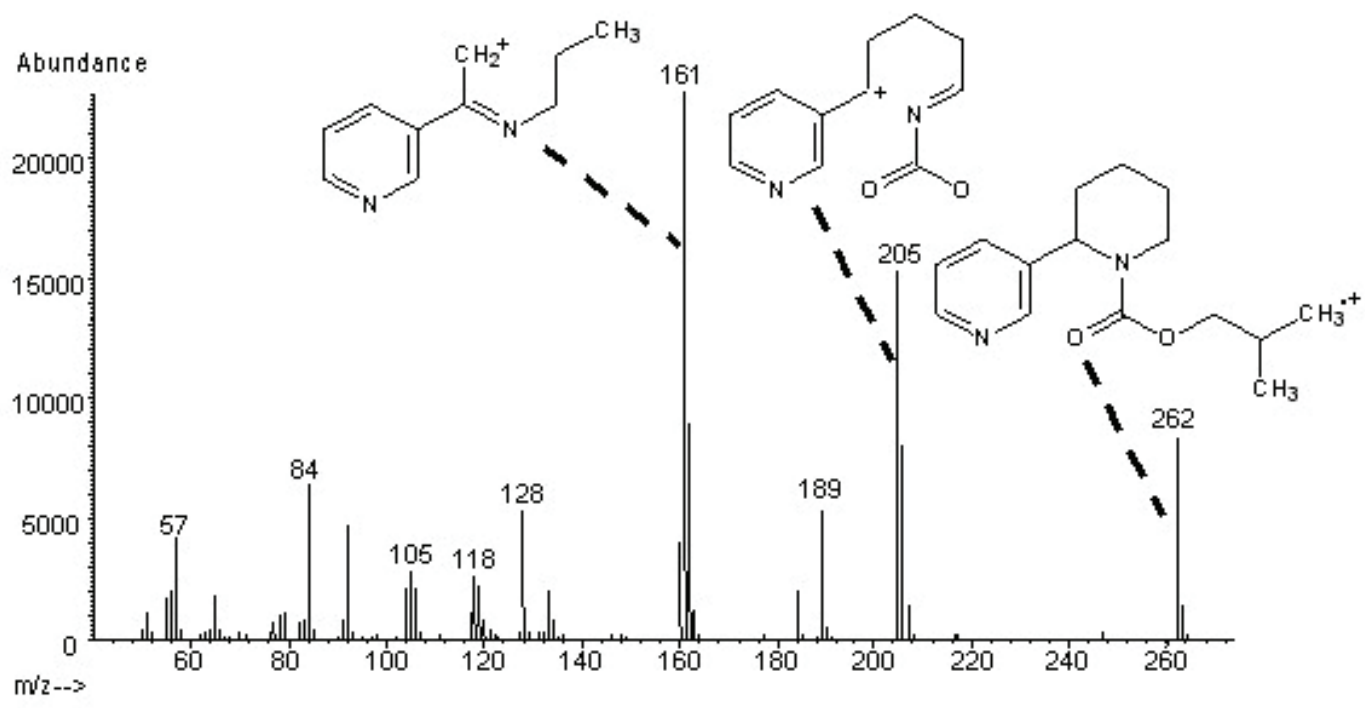

Figure 5. Mass spectrum of isobutyl chloroformate derivative of anabasine or 2-methylpropyl -2-(pyridin-3-yl)piperidine-1carboxylate.

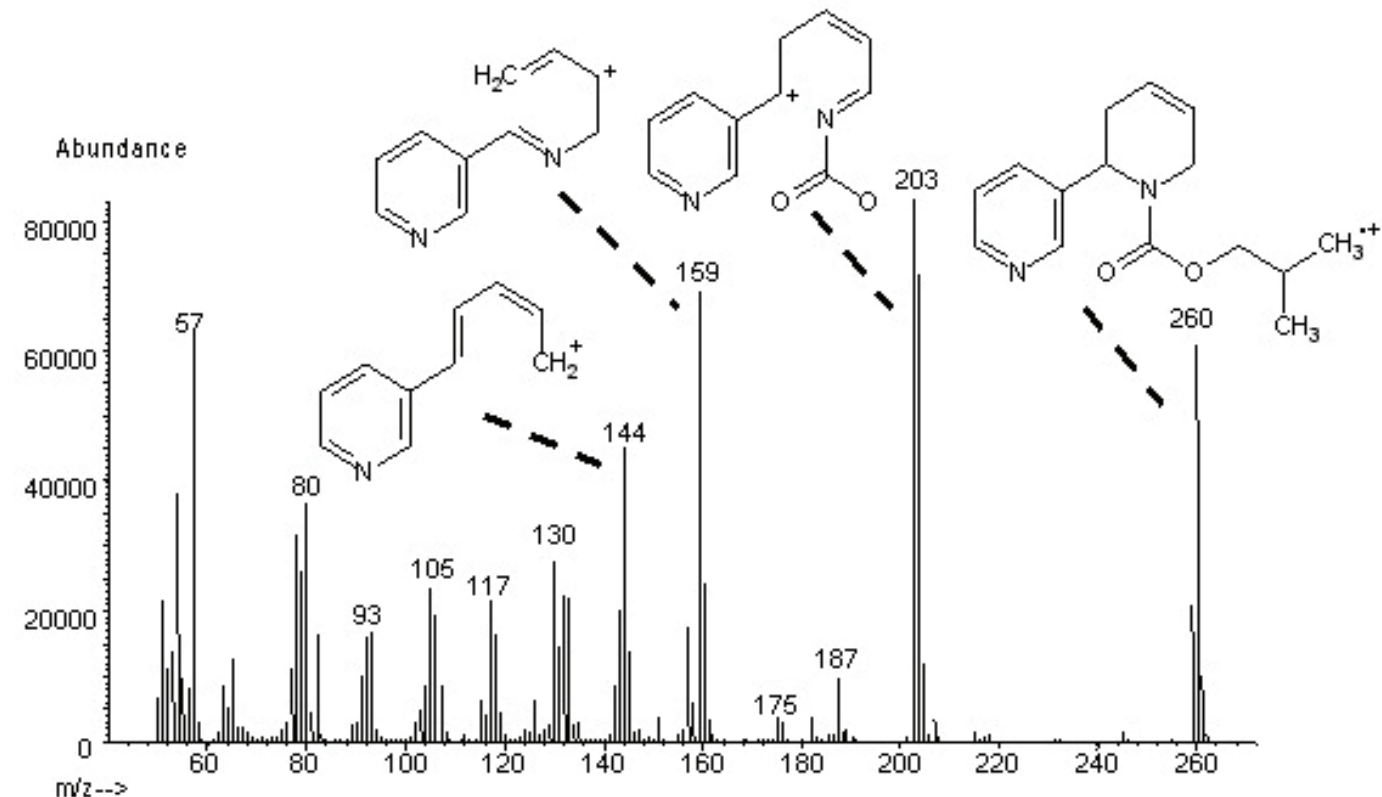

Figure 6. Mass spectrum of isobutyl chloroformate derivative of anatabine or 2-methylpropyl 2-(pyridin-3-yl)-3,6-dihydro-2Hpyridine-1-carboxylate.

Table 5. The ions used for quantitation, the equations used for the calibration, and $\mathbf{R}^{2}$ values for the trendline in Method 2.

\begin{tabular}{l|c|c|c|c|c}
\hline No. & Compound & Quantitation ion & Confirmation ions & Equation* & $R^{2}$ \\
\hline 1 & R-nornicotine & 191 & $193,249,247$ & $\mathrm{Y}=1.0939 \mathrm{e}-5 \mathrm{X}$ & 0.9892 \\
2 & S-nornicotine & 191 & $193,248,247$ & $\mathrm{Y}=1.0999 \mathrm{e}-5 \mathrm{X}$ & 0.9919 \\
3 & Anabasine & 161 & 205,262 & $\mathrm{Y}=3.8700 \mathrm{e}-6 \mathrm{X}$ & 0.9883 \\
4 & Anatabine & 203 & 260,159 & $\mathrm{Y}=1.14342 \mathrm{e}-5 \mathrm{X}$ & 0.9855 \\
5 & 3-Quinolinic acid ethyl ester (I.S.) & 201 & $156,173,128$ & & \\
\hline
\end{tabular}

${ }^{*}$ Note: $\mathrm{Y}$ represents the amount in $\mathrm{mg} \mathrm{mL}^{-1}$ and $\mathrm{X}$ the peak area. 
Table 6. Averages for the level of nornicotine (total), anabasine and anatabine with samples analyzed in an interval of $48 \mathrm{~h}$.

\begin{tabular}{|c|c|c|c|c|c|c|c|c|c|c|}
\hline No. & Sample & $\begin{array}{c}\text { Time after } \\
\text { derivatization } \\
\mathrm{h}\end{array}$ & $\begin{array}{c}\text { Average } \\
\text { R-nornicot. } \\
\mu \mathrm{g} \mathrm{g}^{-1}\end{array}$ & $\begin{array}{c}\text { RSD\% } \\
\text { R-nornicot. }\end{array}$ & $\begin{array}{c}\text { Average } \\
\text { S-nornicot. } \\
\mu \mathrm{g} \mathrm{g}^{-1}\end{array}$ & $\begin{array}{c}\text { RSD\% } \\
\text { S-nornicot. }\end{array}$ & $\begin{array}{c}\text { Average } \\
\text { anabasine } \\
{\mu \mathrm{g} \mathrm{g} \mathrm{g}^{-1}}^{-}\end{array}$ & $\begin{array}{c}\text { RSD\% } \\
\text { anabasine }\end{array}$ & $\begin{array}{c}\text { Average } \\
\text { anatabine } \\
{\mu \mathrm{g} \mathrm{g}^{-1}}^{-1}\end{array}$ & $\begin{array}{c}\text { RSD\% } \\
\text { anatabine }\end{array}$ \\
\hline 1 & Burley & $0-2$ & 777 & $(2.32)$ & 1750 & $(1.24)$ & 238 & $(2.34)$ & 1901 & $(2.14)$ \\
\hline 2 & Burley & $\sim 12$ & 765 & (3.21) & 1731 & (3.33) & 233 & $(4.21)$ & 1897 & (3.12) \\
\hline 3 & Burley & $\sim 24$ & 766 & $(0.21)$ & 1744 & (1.32) & 211 & (3.33) & 1876 & $(4.16)$ \\
\hline \multicolumn{2}{|c|}{ Total average } & & 769 & $(0.87)$ & 1742 & $(0.56)$ & 227 & $(6.32)$ & 1891 & $(0.71)$ \\
\hline 4 & Flue-cured & $0-2$ & 276 & $(4.23)$ & 577 & $(2.33)$ & 229 & $(4.21)$ & 1440 & $(2.11)$ \\
\hline 5 & Flue-cured & $\sim 12$ & 275 & (3.21) & 568 & $(2.12)$ & 222 & $(1.23)$ & 1421 & (3.11) \\
\hline 6 & Flue-cured & $\sim 24$ & 254 & (2.11) & 559 & (1.55) & 234 & (2.12) & 1409 & $(2.45)$ \\
\hline \multicolumn{2}{|c|}{ Total average } & & 268 & $(4.63)$ & 568 & $(1.58)$ & 228 & (2.64) & 1423 & $(1.10)$ \\
\hline
\end{tabular}

Table 7. Estimated limit of detection (LOD), limit of quantitation (LOQ) for standard solutions and the corresponding LOQ for sample.

\begin{tabular}{l|c|c|c}
\hline Compound & $\begin{array}{c}\mathrm{LOD} \\
\mathrm{mg} \mathrm{mL}^{-1}\end{array}$ & $\begin{array}{c}\mathrm{LOQ} \\
\mathrm{mg} \mathrm{mL}^{-1}\end{array}$ & $\begin{array}{c}\text { Equivalent } \mathrm{LOQ} \\
\text { sample } \mathrm{mg} \mathrm{g}^{-1}\end{array}$ \\
\hline R-nornicotine & 0.26 & 0.84 & 16.8 \\
S-nornicotine & 0.24 & 0.82 & 16.4 \\
Anabasine & 0.30 & 1.02 & 20.4 \\
Anatabine & 0.20 & 0.66 & 13.2 \\
\hline
\end{tabular}

The results for the level of nornicotine, anabasine, and anatabine in the analyzed tobaccos (as is, i.e. wet weight basis) using GC/MS method without enantiomer separation (Method 1) are given in Table 9. All samples were analyzed in duplicate. The results for the level of total nornicotine (R-nornicotine plus S-nornicotine), as well as the levels of anabasine, and anatabine in the analyzed tobaccos using GC/MS method with enantiomer separation (Method 2) are shown in Table 10. These samples were also analyzed in duplicate.

Table 8. Tobaccos analyzed in this study.

\begin{tabular}{|c|c|c|c|}
\hline No & Tobacco identification & Year & Description \\
\hline 1 & By A & 2012 & Burley blend \\
\hline 2 & $\mathrm{FC} \mathrm{A}$ & 2012 & Flue-cured blend \\
\hline 3 & L-FC B & 2008 & Lower stalk (lug) flue-cured B \\
\hline 4 & U-FC B & 2008 & Upper stalk (leaf \& some tips) flue-cured B \\
\hline 5 & L-FC C & 2009 & Lower stalk (lug) flue-cured C \\
\hline 6 & U-FC C & 2009 & Upper stalk (leaf \& some tips) flue-cured C \\
\hline 7 & Off L-FC & 2008 & Offshore*, lower stalk (lugs \& primings) flue-cured \\
\hline 8 & Off U-FC & 2008 & Offshore, upper stalk (leaf \& tips) flue-cured \\
\hline 9 & L-By B & 2007 & Lower stalk (flyings \& cutters) Burley B \\
\hline 10 & U-By B & 2007 & Upper stalk (leaf) Burley B \\
\hline 11 & L-By C & 2008 & Lower stalk (flyings \& cutters) Burley C \\
\hline 12 & U-By C & 2008 & Upper stalk (leaf) Burley C \\
\hline 13 & Off L-By & 2008 & Offshore, lower stalk (flyings \& cutters) Burley \\
\hline 14 & Off U-By & 2008 & Offshore, upper stalk (leaf) Burley \\
\hline 15 & Perique & 2008 & Perique tobacco whole stalk \\
\hline 16 & Dark Air Cured & 2012 & Middle stalk \\
\hline 17 & Fire Cured & $?$ & Upper two thirds of plant \\
\hline 18 & Or A & 2007 & Oriental (middle to upper stalk) A \\
\hline 19 & Or B & 2005 & Oriental (middle to upper stalk) B \\
\hline 20 & Cigarette blend & 2010 & Commercial cigarette \\
\hline 21 & 2R4Fn & 2001 & Tobacco from 2R4F cigarettes kept in freezer \\
\hline 22 & 2R4Fo & 2001 & Tobacco from $2 \mathrm{R} 4 \mathrm{~F}$ cigarettes kept at room temperature \\
\hline 23 & $3 \mathrm{R} 4 \mathrm{~F}$ & 2007 & Tobacco from 3R4F cigarettes kept in freezer \\
\hline 24 & 1R4F & 1983 & Tobacco from 1R4F cigarettes kept in freezer \\
\hline 25 & Green FC & 2011 & Freeze dried green flue-cured tobacco \\
\hline 26 & Green Bu & 2011 & Freeze dried green Burley tobacco \\
\hline 27 & Green Or & 2011 & Freeze dried green Oriental tobacco \\
\hline
\end{tabular}

Note: Offshore tobacco indicates tobaccos from outside US. The Oriental tobacco is also "offshore". 
Table 9. The level of total nornicotine, anabasine, and anatabine analyzed by Method 1.

\begin{tabular}{|c|c|c|c|c|c|c|c|}
\hline No. & Sample Oriental & $\begin{array}{c}\text { Average } \\
\text { nornicotine } \mu \mathrm{g} \mathrm{g}^{-1}\end{array}$ & $\begin{array}{c}\text { RSD\% } \\
\text { nornicotine }\end{array}$ & $\begin{array}{c}\text { Average } \\
\text { anabasine } \mu \mathrm{g} \mathrm{g}^{-1}\end{array}$ & $\begin{array}{c}\text { RSD\% } \\
\text { anabasine }\end{array}$ & $\begin{array}{c}\text { Average } \\
{\text { anatabine } \mu \mathrm{g} \mathrm{g}^{-1}}^{-1}\end{array}$ & $\begin{array}{l}\text { RSD\% } \\
\text { anatabine }\end{array}$ \\
\hline 1 & By A & 2509 & 1.11 & 196 & 0.84 & 1880 & 2.35 \\
\hline 2 & $\mathrm{FC} \mathrm{A}$ & 633 & 0.82 & 184 & 0.91 & 1438 & 1.88 \\
\hline 3 & L-FC B & 297 & 1.11 & 49 & 1.89 & 567 & 2.01 \\
\hline 4 & U-FC B & 2213 & 1.21 & 205 & 0.83 & 1572 & 1.98 \\
\hline 5 & L-FC C & 892 & 1.71 & 94 & 0.89 & 836 & 1.76 \\
\hline 6 & U-FC C & 1666 & 1.87 & 181 & 2.55 & 1273 & 2.24 \\
\hline 7 & Off L-FC & 914 & 0.38 & 124 & 0.40 & 1015 & 0.19 \\
\hline 8 & Off U-FC & 1760 & 4.59 & 231 & 0.79 & 1937 & 3.95 \\
\hline 9 & L-By B & 3580 & 2.38 & 169 & 0.63 & 1825 & 2.54 \\
\hline 10 & U-By B & 3994 & 1.28 & 211 & 1.00 & 2452 & 1.68 \\
\hline 11 & L-By C & 3201 & 1.98 & 168 & 1.35 & 1516 & 2.23 \\
\hline 12 & U-By C & 3581 & 3.29 & 212 & 1.13 & 1774 & 2.19 \\
\hline 13 & Off L-By & 2603 & 2.01 & 88 & 0.30 & 597 & 2.23 \\
\hline 14 & Off U-By & 2414 & 1.21 & 91 & 0.02 & 652 & 1.66 \\
\hline 15 & Perique & 2362 & 3.86 & 169 & 4.79 & 1669 & 4.44 \\
\hline 16 & Dark Air Cured & 1790 & 1.18 & 257 & 1.87 & 1694 & 1.52 \\
\hline 17 & Fire Cured & 1001 & 0.17 & 143 & 0.93 & 1549 & 0.37 \\
\hline 18 & Or A & 2403 & 0.91 & 49 & 1.08 & 861 & 0.97 \\
\hline 19 & Or B & 839 & 1.40 & 28 & 1.57 & 160 & 0.10 \\
\hline 20 & Cigarette blend & 1402 & 0.92 & 118 & 1.73 & 910 & 2.39 \\
\hline 21 & $2 \mathrm{R} 4 \mathrm{Fn}$ & 2401 & 2.67 & 107 & 0.77 & 905 & 2.40 \\
\hline 22 & 2R4Fo & 1822 & 1.33 & 104 & 1.54 & 841 & 1.28 \\
\hline 23 & $3 R 4 F$ & 1696 & 2.32 & 114 & 0.09 & 964 & 2.91 \\
\hline 24 & 1R4F & 1391 & 0.20 & 117 & 0.14 & 889 & 0.53 \\
\hline 25 & Green FC & 78 & 1.08 & 14 & 6.91 & 94 & 0.61 \\
\hline 26 & Green Bu & 47 & 2.71 & 8 & 5.90 & 67 & 0.66 \\
\hline 27 & Green Or & 86 & 2.38 & 7 & 4.65 & 98 & 0.27 \\
\hline
\end{tabular}

A comparison of the data from Table 10 showing the levels of nornicotine, anabasine and anatabine obtained by the (new) Method 2 with the data from Table 9 indicates a very good agreement. The equations for the trendlines and the corresponding $\mathrm{R}^{2}$ values for the linear regressions for individual minor alkaloids between the results obtained with Method 1 versus the results obtained with Method 2 are given in Table 11. The agreement shown in this table indicates that Method 2 provides reliable results for the analysis of the three minor alkaloids evaluated in this study. The RSD\% results (for duplicate samples) indicate the good repeatability of the method.

The results for the level of R-nornicotine and S-nornicotine, shown separately, and the proportion of S-nornicotine relative to total nornicotine are given in Table 12. These results indicate that the proportion of S-nornicotine versus the total level of nornicotine in different tobaccos varies considerably. For the analyzed domestic flue-cured tobaccos, a range from $62.2 \%$ to $71.0 \%$ of S-nornicotine was measured (Note: In this report, US tobaccos are indicated as "domestic" and non-US tobaccos are indicated as "offshore"). Offshore flue-cured tobaccos, however, have a lower proportion of S-nornicotine, between $52 \%$ and
$57 \%$. A wider range of proportions of S-nornicotine was noticed among the analyzed Burley tobacco samples, which ranged between $54 \%$ and $72 \%$. However, offshore Burley had a high level of S-isomer, around $90 \%$. Perique and fire-cured tobaccos showed a proportion of S-nornicotine similar to some analyzed Burley tobaccos. The dark air-cured tobacco (2012 crop) showed an approximately equal proportion of R- and S-nornicotine. Relatively high levels of the S-isomer were seen in Oriental tobaccos (between $81 \%$ and $84 \%$ ). Cigarette blends (a commercial cigarette and several Kentucky reference cigarettes) had S-nornicotine in the range $69 \%$ to $77 \%$. Freeze-dried green tobaccos analyzed in this study had very low levels of nornicotine, and the proportion of Snornicotine versus total nornicotine was between $31 \%$ and $44 \%$. These tobaccos had slightly more R-nornicotine than S-nornicotine. The results for Burley, flue-cured and Oriental tobaccos analyzed in this study are in agreement with the data reported in the literature (21). Also, the data reported for R- and S-nornicotine in this study show the same $\mathrm{R} / \mathrm{S}$ ratio as the results reported in the literature for $\mathrm{R} / \mathrm{S}$ isomers of $N^{\prime}$-nitrosonornicotine in several tobacco blends (16). 
Table 10. The level of total nornicotine, anabasine, and anatabine analyzed by Method 2.

\begin{tabular}{|c|c|c|c|c|c|c|c|}
\hline No. & Sample & $\begin{array}{l}\text { Ave. total } \\
\text { nornicotine }\end{array}$ & $\begin{array}{c}\mathrm{RSD} \% \\
\text { total nornicotine }\end{array}$ & $\begin{array}{c}\text { Ave. anabasine } \\
\mathrm{mg} / \mathrm{g}\end{array}$ & $\begin{array}{c}\text { RSD\% } \\
\text { anabasine }\end{array}$ & $\begin{array}{l}\text { Ave. anatabine } \\
\mathrm{mg} / \mathrm{g}\end{array}$ & $\begin{array}{c}\text { RSD \% } \\
\text { anatabine }\end{array}$ \\
\hline 1 & By A & 2527 & 1.24 & 238 & 2.34 & 1901 & 2.14 \\
\hline 2 & $\mathrm{FC} \mathrm{A}$ & 626 & 3.21 & 229 & 4.21 & 1440 & 2.11 \\
\hline 3 & L-FC B & 288 & 2.01 & 65 & 2.21 & 576 & 0.89 \\
\hline 4 & U-FC B & 2234 & 1.08 & 205 & 0.80 & 1527 & 0.00 \\
\hline 5 & L-FC C & 914 & 2.56 & 96 & 1.10 & 836 & 1.67 \\
\hline 6 & U-FC C & 1612 & 5.42 & 174 & 6.71 & 1265 & 4.06 \\
\hline 7 & Off L-FC & 840 & 3.91 & 106 & 6.97 & 935 & 8.10 \\
\hline 8 & Off U-FC & 1776 & 5.01 & 242 & 4.11 & 1972 & 3.58 \\
\hline 9 & L-By B & 3609 & 0.69 & 177 & 3.96 & 1839 & 4.30 \\
\hline 10 & U-By B & 4106 & 5.23 & 229 & 3.59 & 2411 & 4.81 \\
\hline 11 & L-By C & 3227 & 2.00 & 175 & 1.25 & 1511 & 2.28 \\
\hline 12 & U-By C & 3623 & 5.08 & 204 & 3.78 & 1730 & 3.16 \\
\hline 13 & Off L-By & 2638 & 1.70 & 83 & 0.73 & 578 & 1.74 \\
\hline 14 & Off U-By & 2352 & 3.76 & 81 & 1.95 & 645 & 1.58 \\
\hline 15 & Perique & 2387 & 6.03 & 159 & 3.18 & 1545 & 6.08 \\
\hline 16 & Dark Air Cured & 1822 & 1.63 & 243 & 2.82 & 1637 & 0.34 \\
\hline 17 & Fire Cured & 1037 & 3.71 & 176 & 2.23 & 1694 & 2.33 \\
\hline 18 & Or A & 2462 & 2.38 & 84 & 1.90 & 829 & 4.48 \\
\hline 19 & Or B & 895 & 1.45 & 34 & 3.63 & 157 & 5.21 \\
\hline 20 & Cigarette blend & 1457 & 1.95 & 115 & 1.37 & 867 & 1.73 \\
\hline 21 & $2 \mathrm{R} 4 \mathrm{Fn}$ & 2411 & 5.18 & 108 & 5.85 & 878 & 4.09 \\
\hline 22 & 2R4Fo & 1889 & 0.99 & 104 & 0.10 & 826 & 1.70 \\
\hline 23 & $3 \mathrm{R} 4 \mathrm{~F}$ & 1672 & 2.34 & 108 & 1.27 & 922 & 0.65 \\
\hline 24 & 1R4F & 1410 & 3.58 & 108 & 1.59 & 858 & 2.83 \\
\hline 25 & Green FC & 91 & 3.06 & $\sim 14^{*}$ & 2.93 & 101 & 4.28 \\
\hline 26 & Green Bu & 49 & 5.46 & $\sim 8^{*}$ & 3.36 & 58 & 1.69 \\
\hline 27 & Green Or & 93 & 0.03 & $\sim 9^{*}$ & 3.84 & 86 & 0.78 \\
\hline
\end{tabular}

* Note: The result is below the LOQ level, and therefore only approximated.

Table 11. The equations of trendlines and $R^{2}$ values for the dependence between the results obtained by the two analytical methods for minor alkaloids analysis.

\begin{tabular}{l|c|c|c}
\hline No. & Compound & Equation $^{*}$ & $\mathrm{R}^{2}$ \\
\hline 1 & Nornicotine & $\mathrm{Y}=1.0108 \mathrm{X}$ & 0.9989 \\
2 & Anabasine & $\mathrm{Y}=1.0336 \mathrm{X}$ & 0.9492 \\
3 & Anatabine & $\mathrm{Y}=0.9892 \mathrm{X}$ & 0.9947 \\
\hline
\end{tabular}

*Note: $X$ represents the results of Method 1 , and $Y$ the results of Method 2.

\section{CONCLUSIONS}

A new method for the analysis of nornicotine, anabasine and anatabine has been developed and partially validated. The method allows separate quantitation for S-nornicotine and R-nornicotine. In terms of accuracy, this procedure compares very favorably with a technique commonly used for minor alkaloids analysis (6). The proportion of Snornicotine in the total nornicotine present in tobacco varies depending on the tobacco type between $52.6 \%$ for an offshore flue-cured tobacco to $91.4 \%$ for an offshore Burley. Green tobaccos (freeze-dried) showed lower levels of S-nornicotine, between $31.6 \%$ and $43.8 \%$ of the total nornicotine (in the analyzed samples).

\section{REFERENCES}

1. Saunders, J.A. and D.E. Blume: Quantitation of Major Tobacco Alkaloids by High-Performance Liquid Chromatography; J. Chromatogr. 205 (1981) 147-154.

2. Wu, W., D.L. Ashley, and C.H. Watson: Determination of Nicotine and Other Minor Alkaloids in International Cigarettes by Solid-Phase Microextraction and Gas Chromatography/Mass Spectrometry; Anal. Chem. 74 (2002) 4878-4884.

3. Pakhale, S.S. and G.B. Maru: Distribution of Major and Minor Alkaloids in Tobacco, Mainstream and Sidestream Smoke of Popular Indian Smoking Products; Food Chem. Toxicol. 36 (1998) 1131-1138.

4. Yang, S.S. and I. Smetena: Evaluation of Capillary Electrophoresis for the Analysis of Nicotine and Selected Minor Alkaloids from Tobacco; Chromatographia 40 (1995) 375-378.

5. Sheng, L.Q., L. Ding, H.W. Tong, G.P. Yong, X.Z. Zhou, and S.M. Liu: Determination of Nicotine-Related Alkaloids in Tobacco and Cigarette Smoke by GC-FID; Chromatographia 62 (2005) 63-68.

6. Chen, P.X., N. Qian, H.R. Burton, and S.C. Moldoveanu: Analysis of Minor Alkaloids in Tobacco: A Collaborative Study; Beitr. Tabakforsch. Int. 21 (2005) 369-379. 
Table 12. The level of R-nornicotine, S-nornicotine and the proportion of S-nornicotine vs. total.

\begin{tabular}{|c|c|c|c|c|c|c|}
\hline No. & Sample & $\begin{array}{l}\text { Ave. R-nornicotine } \\
\qquad \mathrm{\mu g} \mathrm{g}^{-1}\end{array}$ & $\begin{array}{c}\text { RSD\% } \\
\text { R-nornicotine }\end{array}$ & $\begin{array}{c}\text { Ave. S-nornicotine } \\
\mathrm{\mu g} \mathrm{g}^{-1}\end{array}$ & $\begin{array}{c}\text { RSD\% } \\
\text { S-nornicotine }\end{array}$ & $\begin{array}{c}\text { S-nornicotine/ } \\
\text { nornicotine total \% }\end{array}$ \\
\hline 1 & By A & 777 & 2.32 & 1750 & 1.24 & 69.3 \\
\hline 2 & $\mathrm{FC} \mathrm{A}$ & 202 & 4.23 & 422 & 2.33 & 67.6 \\
\hline 3 & L-FC B & 99 & 2.41 & 189 & 3.22 & 65.6 \\
\hline 4 & U-FC B & 649 & 2.22 & 1585 & 1.86 & 71.0 \\
\hline 5 & L-FC C & 347 & 2.34 & 567 & 2.86 & 62.2 \\
\hline 6 & U-FC C & 523 & 7.29 & 1089 & 6.00 & 67.6 \\
\hline 7 & Off L-FC & 398 & 5.14 & 442 & 9.50 & 52.6 \\
\hline 8 & Off U-FC & 758 & 3.79 & 1018 & 5.92 & 57.3 \\
\hline 9 & L-By B & 1478 & 0.58 & 2132 & 0.77 & 59.1 \\
\hline 10 & U-By B & 1856 & 4.40 & 2250 & 5.92 & 54.8 \\
\hline 11 & L-By C & 916 & 3.37 & 2311 & 1.46 & 71.6 \\
\hline 12 & U-By C & 1013 & 3.68 & 2610 & 5.63 & 72.0 \\
\hline 13 & Off L-By & 227 & 3.05 & 2411 & 1.57 & 91.4 \\
\hline 14 & Off U-By & 238 & 0.56 & 2114 & 4.12 & 89.9 \\
\hline 15 & Perique & 1016 & 1.84 & 1371 & 1.47 & 57.5 \\
\hline 16 & Dark Air Cured & 914 & 4.44 & 908 & 2.96 & 49.8 \\
\hline 17 & Fire Cured & 430 & 3.74 & 607 & 1.42 & 58.6 \\
\hline 18 & Or A & 403 & 9.00 & 2059 & 5.45 & 83.6 \\
\hline 19 & Or B & 166 & 1.93 & 729 & 2.22 & 81.4 \\
\hline 20 & Cigarette blend & 454 & 2.03 & 1003 & 1.92 & 68.8 \\
\hline 21 & $2 \mathrm{R} 4 \mathrm{Fn}$ & 622 & 4.21 & 1789 & 5.52 & 74.2 \\
\hline 22 & 2R4Fo & 460 & 1.58 & 1429 & 0.80 & 75.7 \\
\hline 23 & $3 \mathrm{R} 4 \mathrm{~F}$ & 508 & 4.61 & 1163 & 1.36 & 69.6 \\
\hline 24 & 1R4F & 329 & 4.06 & 1081 & 3.44 & 76.7 \\
\hline 25 & Green FC & 53 & 5.61 & 38 & 0.50 & 41.7 \\
\hline 26 & Green Bu & 34 & 2.32 & $\sim 16^{*}$ & 4.81 & 31.6 \\
\hline 27 & Green Or & 52 & 2.76 & 41 & 3.62 & 43.8 \\
\hline
\end{tabular}

* Note: The result is very close to the LOQ level, and therefore only approximated.

7. Gorrod, J.W. and P. Jacob III (Eds.): Analytical Determination of Nicotine and Related Compounds and Their Metabolites; Elsevier, Amsterdam, Netherlands, 1999.

8. Seeman, J.I.: “The Nicotine Analogue Program" - A Review; Revision (January 16, 1995) of original report (June 13, 1994); available at: http://legacy.library. ucsf.edu/documentStore/n/c/t/nct13e00/Snct13e00.pdf, (accessed September 04, 2013).

9. Hoffmann, D., K.D. Brunnemann, B. Prokopczyk, and M.V. Djordjevic: Tobacco-Specific $N$-Nitrosamines and Areca-Derived $N$-Nitrosamines: Chemistry, Biochemistry, Carcinogenicity, and Relevance to $\mathrm{Hu}-$ mans; J. Toxicol. Environ. Health 41 (1994) 1-52.

10. Jacob, P. III, L. Yu, G. Liang, A.T. Shulgin, and N.L. Benowitz: Gas Chromatographic-Mass Spectrometric Method for Determination of Anabasine, Anatabine and Other Tobacco Alkaloids in Urine of Smokers and Smokeless Tobacco Users; J. Chromatogr. 619 (1993) 49-61.

11. Zhang, Y., P. Jacob III, and N.L. Benowitz: Determination of Nornicotine in Smoker's Urine by Gas Chromatography Following Reductive Alkylation to $N^{\prime}$ Propylnornicotine; J. Chromatogr. 525 (1990) 349-357.

12. Siminszky, B., L. Gavilano, S.W. Bowen, and R.E.
Dewey: Conversion of Nicotine to Nornicotine in Nicotiana tabacum is Mediated by CYP82E4, a Cytochrome P450 Monooxygenase; Proc. Natl. Acad. Sci. USA 102 (2005) 14919-14924.

13. Gorrod, J.W. and J. Wahren (Eds.): Nicotine and Related Alkaloids: Absorption, Distribution, Metabolism and Excretion; Chapman \& Hall Ltd., London, UK, 1993.

14. Armstrong, D.W., X. Wang, and N. Ercal: Enantiomeric Composition of Nicotine in Smokeless Tobacco, Medicinal Products, and Commercial Reagents; Chirality 10 (1998) 587-591.

15. Armstrong, D.W., X. Wang, J.-T. Lee, and Y.-S. Liu: Enantiomeric Composition of Nornicotine, Anatabine, and Anabasine in Tobacco; Chirality 11 (1999) 82-84.

16. Stepanov, I., K. Yershova, S. Carmella, P. Upadhyaya, S.S. Hecht: Levels of (S)-N'-Nitrosonornicotine in U.S. Tobacco Products; Nicotine Tob. Res. 15 (2013) 1305-1310.

17. Balbo, S., S. James-Yi, M.G. O’Sullivan, I. Stepanov, M. Wang, S. Zhang, F. Kassie, S. Carmella, C.Wettlaufer, K. Hohol, A. Knezevich, P. Upadhyaya, and S.S. Hecht: (S)-N'-Nitrosonornicotine, a Constituent of Smokeless Tobacco, Is a Potent Oral Tumorigen in Rats; Proc. AACR $103^{\text {rd }}$ Annual Meeting, March 31-April 4, 2012, Chicago, IL, Abstract LB-63, Can- 
cer Res. 72 (8 Suppl. 1) (2012) LB-63.

18. Hoffmann, D. and S.S. Hecht: Nicotine-Derived $N$ Nitrosamines and Tobacco-Related Cancer; Current Status and Future Directions; Cancer Res. 45 (1985) 935-944.

19. Hecht, S.S. and D. Hoffmann: Tobacco-Specific Nitrosamines, an Important Group of Carcinogens in Tobacco and Tobacco Smoke; Carcinogenesis 9 (1988) 875-884.

20. Cai, B., A. Jack, R.S. Lewis, R.E. Dewey, H. Ji, L. Bush: Accumulation of Nicotine and Nornicotine Enantiomers in Leaves of Nicotine Demethylase Mutants During Growth and Curing; $66^{\text {th }}$ Tobacco Science Research Conference, Concord, NC, Sept. 9-12, 2012, Poster No. 13.

21. Späth, E. and F. Kesztler: Über das Vorkommen von $d, l$-Nor-nicotin, $d, l$-Anatabin und $l$-Anabasin im Tabak (XII. Mitteil. über Tabakalkaloide) [On the Presence of $d$,l-Nornicotine, $d, l$-Anatabine and $l$-Anabasine in Tobacco (XII ${ }^{\text {th }}$ Report on Tobacco Alkaloids)]; Ber. Dtsch. Chem. Ges. A/B 70 (1937) 704-709.

22. Tang, Y., W.L. Zielinski, and H.M. Bigott: Separation of Nicotine and Nornicotine Enantiomers via Normal Phase HPLC on Derivatized Cellulose Chiral Stationary Phases; Chirality 10 (1998) 364-369.
23. Perfetti, T.A. and W.M. Coleman III: Chiral-Gas Chromatograpy-Selected Ion Monitoring-Mass Selective Detection Analysis of Secondary Alkaloids in Tobacco and Tobacco Smoke; Beitr. Tabakforsch. Int. 18 (1998) 35-42.

24. Liu, B., C. Chen, D. Wu, and Q. Su: Enantiomeric Analysis of Anatabine, Nornicotine and Anabasine in Commercial Tobacco by Multi-Dimensional Gas Chromatography and Mass Spectrometry; J. Chromatogr. B 865 (2008) 13-17.

25. Cai, J., B. Liu, P. Lin, and Q. Su: Fast Analysis of Nicotine and Related Alkaloids in Tobacco and Cigarette Smoke by Megabore Capillary Gas Chromatography; J. Chromatogr. A 1017 (2003) 187-193.

Address for correspondence:

Serban C. Moldoveanu

R.J. Reynolds Tobacco Co.

950 Reynolds Blvd.

Winston-Salem, NC 27105, USA

E-mail:moldovs@rjrt.com 